\title{
JChain: A new way to look inside the firm
}

\author{
Amabile Francesco $^{1} \quad$ Cervellera Gian Piero ${ }^{2}$ \\ Lazzi Francesca ${ }^{3} \quad$ Mauro Kenneth ${ }^{4}$ \\ Napolitano Alessio ${ }^{5} \quad$ Parenti Daniele $^{6}$
}

${ }^{1}$ Statistician, Siena(Italy), https://www.linkedin.com/in/francescoamabile/

${ }^{2}$ Lecturer of Applied Computer Science - University of Siena, Siena(Italy), https://www.linkedin.com/in/gianpierocervellera/

${ }^{3}$ Statistician, Siena(Italy), https://www.linkedin.com/in/francesca-lazzi/

${ }^{4}$ Statistician, Siena(Italy), https://www.linkedin.com/in/kennethmauro/

${ }^{5}$ Statistician, Siena(Italy), https://www.linkedin.com/in/alessionapolitano/

${ }^{6}$ Statistician, Siena(Italy), https://www.linkedin.com/in/daniele-parenti/

November 16, 2017

\begin{abstract}
JChain takes advantage of the blockchain mechanism to measure all activities into the firm. The idea is that to create a large database where all activities are masured and recorded by means of a Eurocoinbased-payment system.
\end{abstract}




\section{What is the JChain?}

Jchain(abbreviation of Job Chain) is a project with which we want to propose a new way to look inside the firm.

Our idea is to take advantages of the blockchain for business purposes.

To do this, we have to define shortly what blockchain is:

- a system that continuously records the set of transactions among a group of individuals that contribute to its maintenance;

- a system whose transactions can't be edited or deleted by individuals;

- a system where transactions are registered with a unique code called hash.

The blockchain is a new way of doing business transactions in which any party in the system can buy/sell goods or services. The individuals of the system either contribute to maintaing it and act as a control of the correct Exchange between buyer and seller. For example, they can verify that the buyer has the money to buy the product and that the seller has the necessary goods for the exchange. Anyone can buy or sell a good or service (anywhere in the world), moreover the third control figures are supposed to be the individuals of the system itself. Therefore, the system does not require additional transaction costs. Furthermore, every Exchange is recorded in a database and is visible to all the people of the system. The Exchange is carried out by means of the BitCoin. It is a cryptocurrency which is based on the trust coming from the blockchain of the individuals, and it is decentralised by any central bank. The possession of a certain amount of coin is certified by the whole set of holders and the individuals cannot modify such quantity. The fundamental difference between bitcoin and the traditional currency is the emission. In fact there is neither central bank nor government and financial approval.

The system is not hierarchized in the form of clients and servants, but in the form of a peer-to-peer relationship.

The blockchain in synthesis:

1) two subjects (A and B) decide to make a transaction ;

2) the transaction is written in block form;

3) this is shared wih all the users in the network that are part of A and B;

4) users have to verify and validate the transaction; 
5) at this point the block enters the blockchain;

6) and the transaction takes place.

\section{JChain and Eurocoin}

Our idea was born from the operation of the blockchain. We want to introduce a platform that records all the activities within the firm and measures it by means of a virtual firm currency (Eurocoin). With this coin we want to pay for any kind of work done: firm projects, meetings, consultations and more.

The remuneration from the activities is likely to vary on the basis of the demand and supply market law.

A real business deal is also created for the smaller businesses, e.g. short meetings, between two employees. Everybody becomes manager of himself and should pay as such. If the firm uses email as a form of activity request, the amount of Eurocoin should be specified because the appointee have to agree or disagree the task.

An application of the JobChain can be obtained by hypothesizing a hypothetical society that we call Example Ltd. The firm consist of 5 individuals who are the participants of JobChain and are listed below with corresponding income:

- $\mathrm{CEO}, 40$ '000€;

- Head of development, 30’000€;

- Developer 1, 15’000€;

- Developer 2, 15’000€;

- Developer 3, 15’000€.

Below there are examples of possible commissions of Eurocoin trading:

1)The Chief Executive Officer of "Example Ltd" asks the Head of Development a website. The latter is paid 100 Eurocoin for the brainstormin activities; 


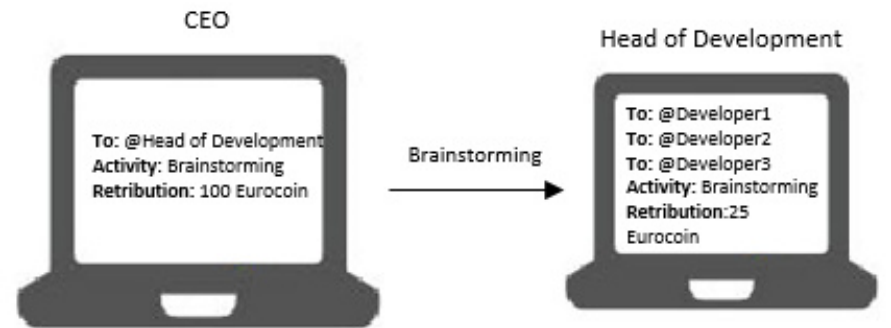

CEO: -100 EuroCoin

Head of Development: +100

EuroCoin

Figure 1: Example of activity 1

2) To do this, Head of Development contacts: two PHP developers paying them 90 Eurocoin, and a Javascript developer by paying 45 Eurocoin for Brainstorming;

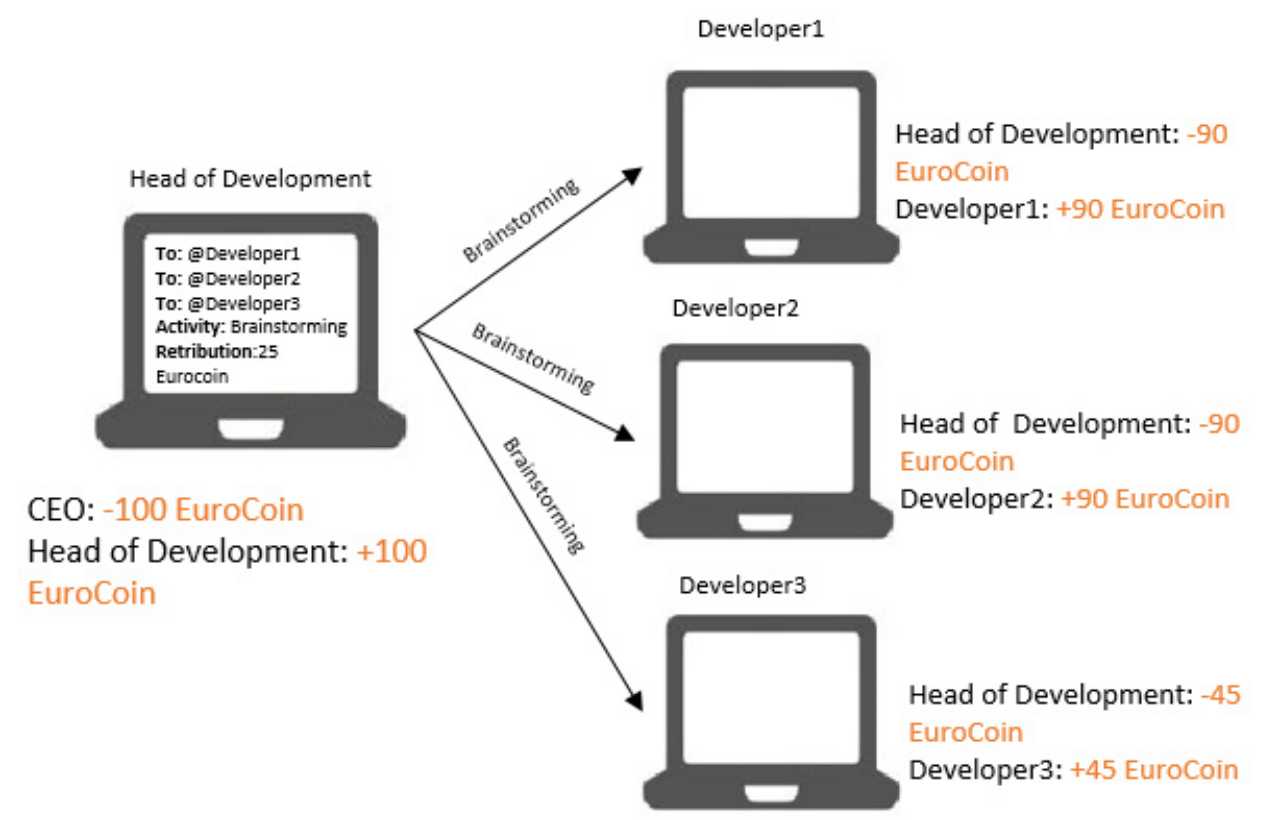

Figure 2: Example of activity 2

Eurocoin's activity and remuneration board is not just topdown, but it can also be horizontal or bottomup as follows:

- Developer1 can consult Developer2 for 10 Eurocoin. 


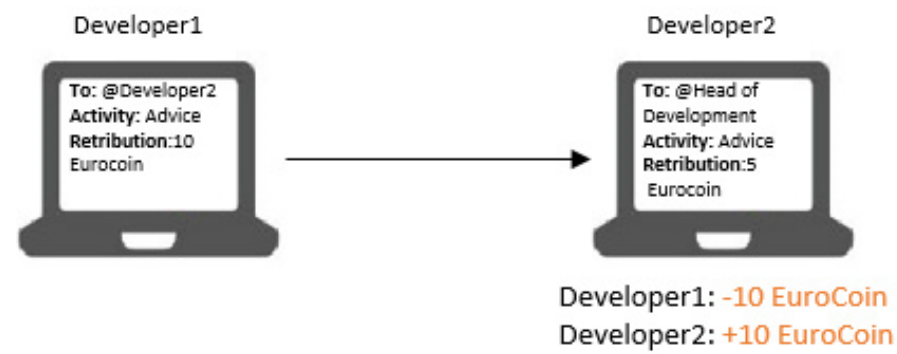

Figure 3: Example of activity 3

- Developer2 may seek advice from Head of Development for 5 Eurocoin.

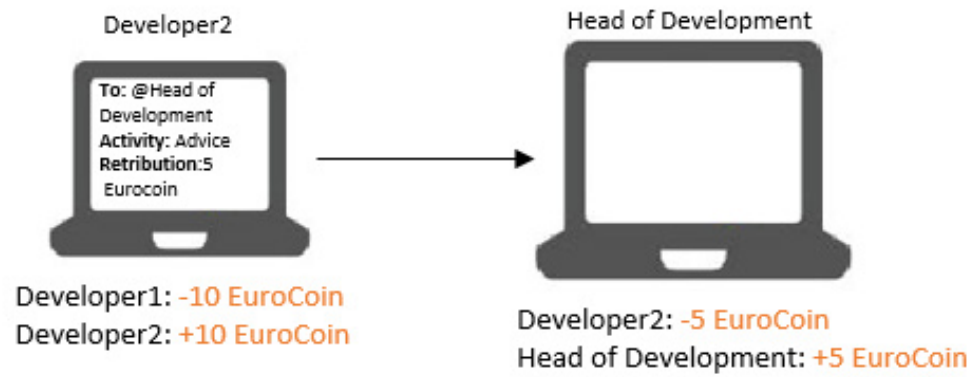

Figure 4: Example of activity 4

So, each activity has a counterpart in Eurocoin. The only exception are the purely informative activities whose remuneration is 0 Eurocoin. As we expected, the natural flow of jobs required in the firm generates a multitude of activities. 


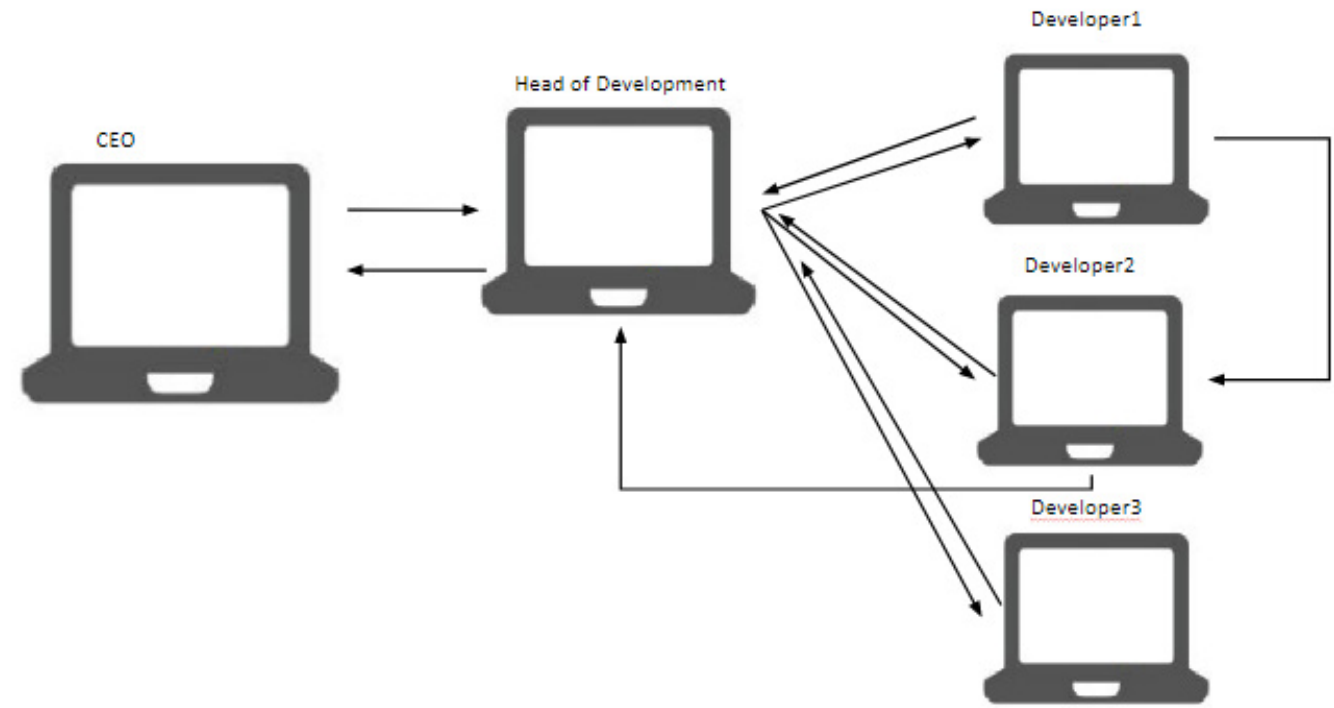

Figure 5: Example of JobChain flow

\section{How we can measure the activities}

With the JChain model, each activity is detected and measured in Eurocoin by setting up a business database(that we call JChainDB). Below there is a simple example:

Table 1: Simple example of JChainDB

\begin{tabular}{c|c|c|c|c|c}
\hline ID & CUSTOMER & CHARGER & ACTIVITY & AMOUNT & CONCLUDED \\
\hline 1 & CEO & $\begin{array}{c}\text { Head of } \\
\text { Development }\end{array}$ & Brainstorming & 100 Eurocoin & Yes \\
\hline 2 & $\begin{array}{c}\text { Head of } \\
\text { Development }\end{array}$ & Developer1 & Brainstorming & 90 Eurocoin & Yes \\
\hline 3 & $\begin{array}{c}\text { Head of } \\
\text { Development }\end{array}$ & Developer2 & Development & 1000 Eurocoin & In Progress \\
\hline 4 & $\begin{array}{c}\text { Head of } \\
\text { Development }\end{array}$ & Developer3 & Brainstorming & 90 Eurocoin & No \\
\hline$\ldots$ & $\ldots$ & $\ldots$ & $\ldots$ & $\ldots$ & $\ldots$
\end{tabular}




\section{Model's output}

\subsection{JChain model}

Analyzing the database presented in last section, we illustrate below a possible output of the JChain model:

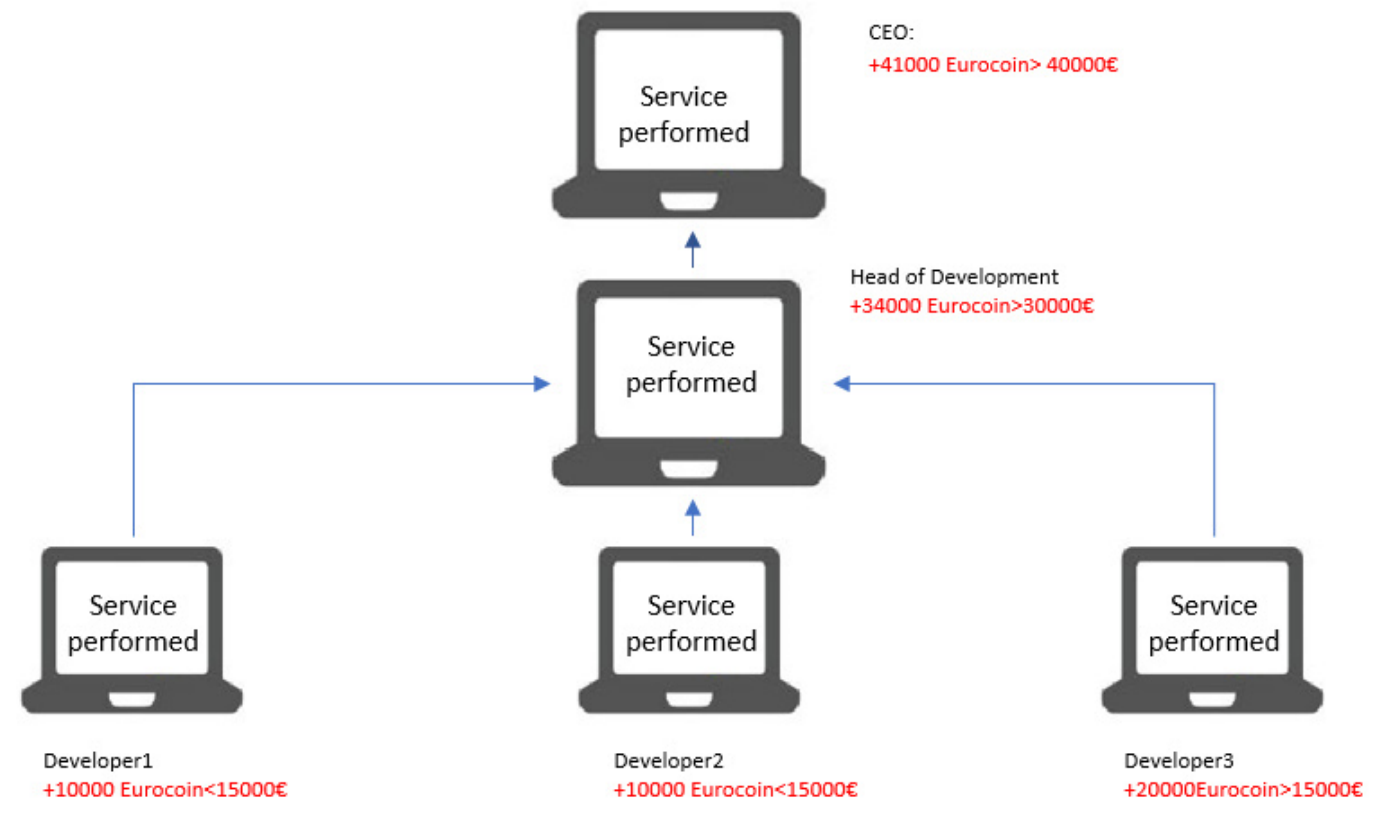

Figure 6: Example of JChain model's output

From the picture it is shown that if the sum of all the activities carried out in one year by a subject, measured in Eurocoin, is higher than his annual salary it is likely that the subject produces more than he is paid. On the contrary, but similarly, if the sum of all the activities carried out in one year by an individual, measured in Eurocoin, is less than his annual salary then the subject produces less than what is paid.

Beyond the example, the potential of this work tool should be evident, by analyzing the database, in fact it is possible:

- to have full control over society;

- to measure efficiencies and inefficiencies;

- to distribute equally premiums or variable parts of remuneration;

- to check the importance of each individual subject / office. 


\subsection{Customers/Appointees Matrix}

The "Customers/Appointees Matrix"(CA matrix) indicates the total flows, in terms of Eurocoin, which are passed from an employee to another one. Moreover, the output of earnings, expenditures, and results are represented below.

The final index shows the importance that the flows' generation attributes to every single employee. In other words, it is the product of earnings' total and the percentage of positives flows' number.

$$
\text { Importance Index } x_{i}=\text { Earnings }_{i} \cdot \frac{\sum_{j=1}^{C} x_{i j}}{C}
$$

Where:

$$
\begin{aligned}
& C=\text { Card }(\text { Individuals })-1 \\
& x_{i j}=\left\{\begin{array}{l}
1 \text { if Earnings } \text { E }_{i j}>0 \\
0 \text { ifEarnings }_{i j}=0
\end{array}\right.
\end{aligned}
$$

Next, we show in Figure 7 the representation of the customer/appointees matrix, immediately after, in Figure 8 we represent the JChain output with

\begin{tabular}{|c|c|c|c|c|c|c|c|}
\hline & \multicolumn{5}{|c|}{ Customers } & \multirow[b]{2}{*}{ EARNINGS } \\
\hline & & CEO & HOD & D1 & D2 & D3 & \\
\hline \multirow{5}{*}{ 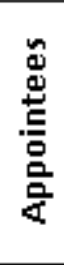 } & CEO & - & - & - & - & - & - \\
\hline & HOD & 75 & - & 1 & 1 & - & 77 \\
\hline & D1 & - & 14 & - & 1 & 1 & 16 \\
\hline & D2 & - & 18 & - & - & - & 18 \\
\hline & D3 & - & 15 & - & 1 & - & 16 \\
\hline & EXPENDITURE & 75 & 47 & 1 & 3 & 1 & \\
\hline
\end{tabular}
importance index. We will explain a possible interpretation of the result in the section "Conclusion".

Figure 7: CA Matrix (all amounts are in thousand EUR) 


\begin{tabular}{|c|c|c|c|c|c|}
\hline & & EARNINGS & EXPENDITURE & RESULT & $\begin{array}{l}\text { IMPORTANCE } \\
\text { INDEX }\end{array}$ \\
\hline \multirow{5}{*}{ 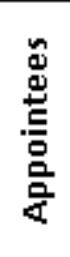 } & CEO & - & 75 & -75 & - \\
\hline & HOD & 77 & 47 & 30 & 57.75 \\
\hline & D1 & 16 & 1 & 15 & 12.00 \\
\hline & D2 & 18 & 3 & 15 & 4.50 \\
\hline & D3 & 16 & 1 & 15 & 8.00 \\
\hline
\end{tabular}

Figure 8: JChain output (all amounts are in thousand EUR)

\section{Conclusion}

Although the example is applied to a simple company, it can be implemented to all companies of all sizes.

The proposed output, the CA matrix and the importance index, are just a possible output that you can have with the JchainDB, as well as the interpretation of the results.

In our example, there are no inefficiencies, since at the end of the year all employees receive a salary in Eurocoin equal to the expected salary. On the other hand, Developer1 seems to be more important than the other developers because he has a higher importance index.

In real companies we do not expect that the salary in Eurocoin is equal to the expected salary but, we expect there are substantial differences.

This is because, at the first sight, the product has to be learned so that (this will be the most complex part of companies) each employee become aware of his/her working ability to formulate an appropriated price to the activity required. Secondly, it is because of the different individual capacities of each employee who propose different prices.

With this method we can measure and know the inefficiencies.

Finally, in the most evolved companies, we might think that in the JChainD$\mathrm{B}$ there is also a field to detect the project and we can have an additional information elements through the CA matrix.

Through the CA matrix we can understand what is the total cost and the most important employee for each project. Other applications to the JChainDB analysis are endless, so we let to the reader immagine them. 


\section{Contents}

\begin{tabular}{lll}
\hline What is the JChain? & 1
\end{tabular}

2 JChain and Eurocoin 2

$\begin{array}{|ll|}3 \text { How we can measure the activities } & 5\end{array}$

$\begin{array}{llr}4 & \text { Model's output } & 6\end{array}$

4.1 JChain model . . . . . . . . . . . . . . . . . . . . . . . 6

4.2 Customers/Appointees Matrix . . . . . . . . . . . . . . . 7

$\begin{array}{llr}5 \text { Conclusion } & 8\end{array}$ 